\title{
Drought and Groundwater Management ${ }^{1}$
}

By

\author{
Eirik S. Amundsen ${ }^{2,3}$ and Frank Jensen ${ }^{3}$
}

JEL classification: Q20, Q22

Keywords: drought, groundwater management, uncertainty

Running head: Drought

\begin{abstract}
This paper considers the problem of a water management authority faced with the threat of a drought that hits at an uncertain date. Three management policies are investigated: i) a laissez-faire (openaccess) policy of automatic adjustment through a zero marginal private net benefit condition, ii) a policy of optimal dynamic management ignoring the threat of the drought and relying on automatic adjustments through a zero marginal social net benefit condition, iii) an economically optimal dynamic policy taking account of the threat of a drought. In particular, we show that the optimal pre-drought steady-state equilibrium stock size of water under policy iii) is smaller than under policy ii) and, hence, a precautionary stock size should not be built up prior to the drought.

\footnotetext{
${ }^{1}$ Thanks to professor Lars Gårn Hansen for valuable comments on earlier drafts of this paper.

2 Corresponding author, Department of Economics, University of Bergen, Norway, Fosswinckelsgt. 6, N-5007 Bergen, Tel.:4755589205, e-mail: eirik.amundsen@uib.no.

${ }^{3}$ Department of Food and Resource Economics, University of Copenhagen, Rolighedsvej 25, Frederiksberg, e-mails: esam@ifro.ku.dk, fje@ifro.ku.dk
} 
